Geleneksel Türk içeceklerinde bekletilen laminate geçici restorasyon materyallerinin renk stabilitelerinin karşılaştırılması

\section{Comparison of color stability of laminate temporary restoration materials kept in traditional Turkish beverages}

\author{
Stj. Diş Hekimi Ceyda Atabay \\ Necmettin Erbakan Üniversitesi, \\ Diş Hekimliği Fakültesi, Konya \\ Orcid ID: 0000-0002-2981-2876
}

\section{Dr. Öğr. Üyesi Makbule Tuğba Tunçdemir} Necmettin Erbakan Üniversitesi, Diş Hekimliği Fakültesi, Konservatif Diş Tedavisi A.D., Konya Orcid ID: 0000-0002-0608-3412

\section{Geliş tarihi: 16 Ocak 2018}

Kabul tarihi: 5 Haziran 2018

doi: 10.5505/yeditepe.2019.79663

\section{Yazışma adresi:}

Dr. Öğr. Üyesi Makbule Tuğba Tunçdemir Necmettin Erbakan Üniversitesi, Diş Hekimliği Fakültesi, Konservatif Diş Tedavisi A.D., Konya Karaciğan Mahallesi, Ankara Cd. No:74,

42050 Karatay/Konya

Tel: (0332) 2200025
ÖZET

Amaç: Bu çalışmanın amacı dört farklı geleneksel Türk içeceğinde bekletilen geçici restorasyon materyallerinin renk değişimlerinin karşılaştırılmasıdır.

Gereç ve Yöntem: Dört farklı laminate geçici restorasyon materyalinden (Protemp, Systemp, Integra, Temdent), 13 mm çapında, 2 mm kalınlığında 40'ar adet örnek hazırlandı. Örnekler dört farklı içeceğin içine konulmak üzere ayrıldı (distile su, şalgam, demirhindi şerbeti, Türk kahvesi). Örnekler bu içeceklerin içerisinde 1 hafta ve 4 hafta süreyle bekletildi. Örneklerin içeceklere konulmadan önceki ve sonraki $L *$, $a *$ ve $b$ * değerleri spektrofotometre kullanılarak kaydedildi ve $\Delta \mathrm{E}$ değerleri hesaplandı. Materyal çeşidinin renk değişimi üzerindeki etkisinin tespit edilmesi için tek yönlü varyans analizi ve içecekler arası renk değişimi analizinde ise t-testi ve Mann Whitney $U$ testi uygulandı.

Bulgular: Farklı içeceklerde bekletilen örneklerden elde edilen $\Delta \mathrm{E} *$ değerleri arasında istatistiksel olarak anlamlılık saptandı $(p<0,05)$. Değerlendirme sonucuna göre birinci ve dördüncü hafta değerlerine bakılarak istatistiksel olarak anlamlı bir farklılık tespit edilmedi ( $p>0,05)$. Sadece içeceklerin renk değişimi üzerinde etkisi değerlendirildiğinde en yüksek renk değişimi demirhindi şerbeti solüsyonunda bekletilen örneklerde gözlendi. Materyaller arası değerlendirmede en fazla renk değişimi bis-akril kompozit rezin içerikli Systemp'te gözlendi.

Sonuç: Laminate geçici restorasyonların renk değişimi, kullanılan materyalin çeşidine ve içeceğin tipine göre değişmektedir. İçecekler değerlendirildiğinde en fazla renk değişimi demirhindi şerbeti ve daha sonra da şalgam suyunda, materyaller değerlendirildiğinde en fazla renk değişimi Systemp'te meydana gelmiştir.

Anahtar kelimeler: Geçici restorasyon materyali, laminate, renk değişimi.

\section{SUMMARY}

Aim: The aim of this study is to compare the color stability of temporary restoration materials immersed in four different traditional Turkish beverages.

Materials and Method: $13 \mathrm{~mm}$ diameter, $2 \mathrm{~mm}$ thick, 40 samples were prepared from four different laminate temporary restorative materials (Protemp, Systemp, Integra, Temdent) The samples were divided for put into four different beverages (distilled water, turnip juice, tamarind juice, Turkish coffee). Samples were waited to these beverages for 1 and 4 weeks. The $L * a *$ and $b$ * values were calculated with spectrophotometer before and after the put into drinks and the $\Delta \mathrm{E}$ values were calculated. One way analysis of variance was used to determine the effect of material type on color change and t-test and Mann-Whitney $U$ test were used for color change analysis between beverages.

Results: Statistically significant difference was noticed between the values of $\Delta \mathrm{E} *$ obtained from the samples immersed in 
different beverages $(p<0.05)$. According to evaluation result there were no statistically significant differences were observed between first and fourth weeks. Only when the effect of drinks on the color change was evaluated, the highest color change was observed which in the samples immersed in the tamarind slurry solution. Among the materials evaluated, the most color-change was observed on bis-acryl composite resin based material Systemp.

Conclusion: The color stability of laminate temporary restorations varies according to the type of food drink. When the drinks were evaluated, the most color change was found in the turnip and then tamarind juice and the most color change occured in Systemp when the materials were evaluated.

Keywords: Laminate, temporary restoration material, color stability.

\section{Giriş}

Geçici restorasyon uygulamaları, laminate protezlerin yerleştirilmesinden önce tedavinin vazgeçilmez parçasıdır. ${ }^{1,2}$ Geçici restorasyonlar diş pulpasını ısısal, mekanik ve bakteriyel etkileşimlere karşı korur, prepare edilen dişlerin oklüzal fonksiyon sırasında sağlamlığını korur. ${ }^{3,4} \mathrm{Bu}$ restorasyonlar özellikle estetiğin korunması için oldukça faydalıdır. ${ }^{5}$

Pratikte, geçici restorasyonların kullanımı birkaç günden bir buçuk yıla hatta daha fazla uzatabilmektedir. ${ }^{6}$ Geçici materyalin kalitesinin belirlenmesinde çeşitli unsurlar yer alır. Bu unsurların en önemlisi kullanılan geçici materyalinin renk değişimidir. ${ }^{7,8}$ Dolayısıyla, renk değişimi, estetik açıdan kritik alanda kullanılmak üzere belirli bir geçici malzemenin seçiminde önemli bir kriterdir. ${ }^{9}$ Renk değiştiren bir geçici restorasyon hasta memnuniyetsizliğine ve ek masrafa neden olabilir. ${ }^{10}$ Bu nedenle geçici restorasyonların kullanım süresi boyunca renk değişimini koruması gerekir ve özellikle uzun süreli kullanımda renk değişikliğinin en aza indirgenmesi istenmektedir. ${ }^{11}$

Uzun süreli kullanımda renk değişikliğine neden olan faktörler; leke birikimi, su emilimi, bileşenlerin çözünmesi, iç pigmentlerin bozulması ve yüzey pürüzlülüğü olarak sayılabilir. ${ }^{12}$ Renk değişikliklerinin değerlendirilmesi, görsel inceleme açısından öznel bir süreçtir. Buna karşılık, spektrofotometre, bir renk değerlendirme cihazı olarak kullanılır ve öznel yorumları ortadan kaldırarak küçük renk farklarının belirlenmesini sağlar. ${ }^{13}$

Geçici restoratif materyallerin renk değişimini ölçmek için literatürde çeşitli çalışmalar yapılmıştır ve bundan önceki çalışmalarda elde edilen sonuçlar oldukça farklılık göstermektedir. ${ }^{14,15}$ Yaptığımız bu çalışma ile en çok kullanılan 4 farklı geçici restoratif materyalin, çeşitli geleneksel Türk içeceklerinde (şalgam suyu, Türk kahvesi, demirhindi şerbeti) bekletilerek klinik uygulamada renk değişimini karşılaştırmak amaçlandı. Bu ölçümler sayesinde geçicile- rin ağızda kalma süreleri de göz önünde bulundurularak direkt ve indirekt yöntemle yapılan geçici materyallerinin renk değişimlerinin karşılaştırması sağlandı.

\section{GEREÇ VE YÖNTEM}

Bu çalışmada 4 farklı içeceğin (distile su, şalgam suyu, demirhindi şerbeti ve Türk kahvesi), 2 farklı direkt yöntemle uygulanan geçici materyalinin (Protemp ${ }^{\text {TM }} 4$ Temporization Materials (3M ESPE), Ivoclar Vivadent Systemp ${ }^{\circledR} . c \& b$ II ) ve 2 farklı indirekt yöntemle uygulanan geçici materyalinin (INTEGRA Temporary And Crown Acrylic, Schütz Temdent Classic) renk değişimi üzerindeki etkisi değerlendirildi.

Kullanılan geçici materyallerinden Protemp, Bis-akril kompozit rezin; Systemp, Bis-akril kompozit rezin; Integra, polimetilmetakrilat; Temdent, polimetilmetakrilattır. Malzemeler ve üreticiler Tablo 1'de özetlenmektedir.

Tablo 1. Kullanılan geçici materyallerin içerikleri ve üretici firmaları.
\begin{tabular}{|l|l|l|}
\hline Materyal & İcerikler & Üretici Firmalar \\
\hline Protemp & Bis-akril kompozit rezin & 3M ESPE,Seefeld,Almanya \\
\hline Systemp & Bis-akril kompozit rezin & $\begin{array}{l}\text { Ivoclar } \\
\text { Vivadent,Schaan,Lihtenştayn }\end{array}$ \\
\hline Integra & Polimetilmetakrilat & $\begin{array}{l}\text { Birleşik Grup Dental, } \\
\text { Ankara,Türkiye }\end{array}$ \\
& & $\begin{array}{l}\text { Schütz Dental } \\
\text { GmbH,Rosbach,Almanya }\end{array}$ \\
\hline Temdent & Polimetilmetakrilat & \\
& &
\end{tabular}

Çalışmada kullanılan her bir geçici materyalinden 40'ar adet olmak üzere toplam 160 örnek hazırlandı. Örnekler; Integra ve Temdent materyalleri için üretici firmaların talimatlarına uygun olarak likit ve toz akril materyallerin karıştırılması ile, Systemp ve Protemp materyalleri için üretici firmaların özel tabancalı aparatları ile kalıplara sıkılarak hazırlandı. Bu amaçla $13 \mathrm{~mm}$ çapında, $2 \mathrm{~mm}$ kalınlığında yuvarlak şekilli kalıplarda geçici örnekleri elde edildi. Tüm örnekler, her bir üretici firmanın talimatlarına göre oluşturuldu. Tüm örnek yüzeylerinde parlak ve standart bir yüzey elde etmek amacıyla yüzeyler ince grenli jumbo akrilik parlatma lastiği ile parlatıldı. Örnekler 24 saat boyunca 37 ${ }^{\circ} \mathrm{C}$ de distile suda bekletildi.

Tüm örneklerin renk ölçümleri CIELAB sistemi ile dental spektrofotometre kullanılarak ölçüldü (Lovibond ${ }^{\circledR}$ Colour Measurement Tintometer ${ }^{\circledR}$ Group). Cihaz, kolorimetrik ölçümlerden önce beyaz daha sonra siyah kalibrasyon plakası ile kalibre edildi. Her bir örnek yüzeyinde ölçümler 3 kere tekrarlanarak ortalama $L$, a ve $b$ değerleri kaydedildi. Farklı çözeltilerdeki renk değişimini değerlendirmek için, her gruptan 40 örnek, her biri farklı solüsyonlar için 10 örnekten oluşan dört alt gruba ayrıldı.

Başlangıç renk değerlerinin ölçümünden sonra 4 farklı içecek hazırlandı. Kullanılan içecekler ve içerikleri Tablo 2'de belirtildi. 
Tablo 2. Kullanılan içecek, içerikleri ve üretici firmaları.

\begin{tabular}{|l|l|l|}
\hline İçecek & İçerikler & Üretici firmalar \\
\hline Şalgam suyu & $\begin{array}{l}\text { Su, mor havuç, şalgam } \\
\text { turpu, tuz, bulgur, koruyucu } \\
\text { (sodyum benzoat) }\end{array}$ & $\begin{array}{l}\text { Doğanay Gida Tarım ve } \\
\text { Hayvancılık San. Tic. A.Ş. } \\
\text { Sarı̧̧am, ADANA }\end{array}$ \\
\hline Demirhindi şerbeti & $\begin{array}{l}\text { Demirhindi, su, şeker, } \\
\text { portakal kabuğu, çeşitli } \\
\text { baharatlar (zencefil kökü, } \\
\text { zerdeçal kökü, tarçın sopası, } \\
\text { karanfil, yenibahar, kakule } \\
\text { tohumu, gül suyu, rezene, } \\
\text { anason) }\end{array}$ & Rifat Minare Konserve \\
& Fabrikası Koll. ŞTİ. Gemlik, \\
\hline Türk kahvesi & Ögütülmüus kahve çekirdeği & Kuru Kahveci Mehmet \\
& & Efendi Mahdumlari Limited \\
& Şirketi, Eminönü, İstanbul \\
\hline
\end{tabular}

1. Distile su; kontrol grubu.

2. Şalgam suyu; (Doğanay Gıda Tarım ve Hayvancılık San. Tic. A.Ş Sarıçam, Adana)

3. Demirhindi şerbeti; (Rifat Minare Konserve Fabrikası Koll. ŞTi. Gemlik, Bursa)

4. Türk kahvesi; 6 gr kahve (Kuru Kahveci Mehmet Efendi Mahdumlari Limited Şirketi, Eminönü, İstanbul) $65 \mathrm{ml}$ suda kaynatılarak hazırlandı.

Renk ölçümleri 1. gün, 1. hafta ve 4. haftada yapıldı. Örnekler renk ölçümlerinden önce kurutma kâğıdı ile kurutuldu. Daha sonra aynı şekilde örneklerin $L$, a, b değerleri ölçülerek ortalamaları kaydedildi. Renk farklııkları aşağıdaki formül kullanılarak hesaplandı: ${ }^{4,16,17}$

\section{$\Delta \mathrm{E} *=[(\mathrm{L} 1 *-\mathrm{L} 0 *) 2+(\mathrm{a} 1 *-\mathrm{a} 0 *) 2+(\mathrm{b} 1 *-\mathrm{b} 0 *) 2] 1 / 2$}

L1, a1 ve b1 değerleri, örneklerin içeceklerde bekletme sonrası $C I E L \star a * b *$ değerlerini; $L 0$, a0 ve b0 değerleri ise başlangıçta ölçülen CIE $L * a * b *$ değerlerini temsil etmektedir. CIE $L * a * b *$ renk uzayı, üç boyutlu bir gösterimi kullanarak görünür ışık aralığında insan gözü tarafından algılanan tüm renkleri gösterir. $L$ * bir cismin açıklık derecesini açıklar; a * değeri kırmızı ile yeşil arasındaki renk pozisyonunu, $b$ * sarı ile mavi arasındaki renk pozisyonunu belirtir. ${ }^{18}$

Materyal faktörlerinin renk değişimi üzerindeki etkisi tek yönlü varyans analizi (ANOVA) ile bir istatistik yazılımı (SPSS 18.0 for Windows; IBM Corp, SPSS Inc, Chicago, IL, ABD) kullanılarak değerlendirildi. İçecekler arası renk değişimi analizinde ise t-testi ve Mann Whitney $U$ testi uygulandı. İstatistiksel önem $p<0,05$ olarak belirlendi.

Bir spektrofotometre üzerinde kaydedilen renk değişikliği miktarı ile klinik çevre arasındaki ilişkiyi belirlemek için veriler, Ulusal Standartlar Bürosu (USB) sistem birimlerine aşağıdaki gibi dönüştürülmüştür:

UBS unit $=0,92 \times(\Delta \mathrm{E})$

UBS ünitelerine göre renk değişimindeki tanımlanmış açıklamalar Tablo 3'te verilmektedir.
Tablo 3. Ulusal Standartlar Bürosu (UBS) birimleri ve renk değişimine ilişkin açıklamalar.

\begin{tabular}{|l|l|}
\hline Renk farkı & NBS unit \\
\hline izz & $0-0,5$ \\
\hline Hafif & $0,5-1,5$ \\
\hline Fark edilebilir & $1,5-3,0$ \\
\hline Kayda değer & $3,0-6,0$ \\
\hline Fazla & $6,0-12,0$ \\
\hline
\end{tabular}

\section{BULGULAR}

Bu çalışmada dört farklı akrilik rezin geçici materyalinin renk değişikliğine zaman ve farklı içecek solüsyonlarının etkisi gözlenmiştir.

Yapılan tek yönlü varyans analizi (ANOVA) sonucunda; farklı içecek solüsyonlarında değişik sürelerde bekletilen materyal örneklerinden elde edilen $\Delta \mathrm{E} *$ değerleri arasındaki farkın istatistiksel olarak anlamlıı̆ı değerlendirildi. Her bir geçici materyalinin farklı sürelerde solüsyonlar içinde renk değişikliği Tablo 4'te gösterildi.

Tablo 4. İçecek farkı gözetmeksizin materyallerde meydana gelen renk değişimleri.

\begin{tabular}{|l|l|l|}
\hline Materyaller & 1.hafta (SS) & 4.hafta (SS) \\
\hline Protemt & $2,15(1,45)$ & $3,00(1,83)$ \\
\hline System & $3,05(2,67)$ & $4,72(3,54)$ \\
\hline Integra & $2,27(0,53)$ & $3,57(1,58)$ \\
\hline Temdent & $2,30(1,36)$ & $3,05(1,69)$ \\
\hline
\end{tabular}

1. Hafta değerlerine bakılarak tüm materyal gruplarında istatistiksel olarak anlamlı farklılık tespit edilmedi $(p>0,05)$. 4. Hafta değerlerine bakılarak tüm materyal gruplarında istatistiksel olarak anlamlı farklılık tespit edilmedi $(p>0,05)$. Yapılan t-testi ve Mann Whitney U testi sonucunda; farklı içecek solüsyonlarının materyal farkı gözetilmeksizin değişik sürelerde meydana getirdiği renk değişimlerinin $\Delta \mathrm{E}$ * değerleri arasındaki farkın istatistiksel olarak anlamlıı̆ı değerlendirildi. Her bir solüsyonün farklı sürelerde meydana getirdiği renk değişikliği Tablo 5 'te gösterildi.

Tablo 5. Materyal farkı gözetmeksizin içeceklerde meydana gelen renk değişimi.

\begin{tabular}{|l|l|l|}
\hline İcecekler & $\mathbf{1 . h a f t a ~ ( A E ) ~}$ & $\mathbf{4 . h a f t a ~ ( A E ) ~}$ \\
\hline Distile su & 0,67 & 0,90 \\
\hline Şalgam suyu & 2,95 & 4,20 \\
\hline Demirhindi şerbeti & 2,17 & 3,32 \\
\hline Türk kahvesi & 3,35 & 4,85 \\
\hline
\end{tabular}

Distile su grubu 1.hafta ve 4. hafta verilerinde istatistiksel olarak anlamlı farklılık tespit edilmedi $(p>0,05)$. Şalgam grubu 1.hafta ve 4. hafta verilerinde istatistiksel olarak anlamlı farklılık tespit edildi. 4. hafta değerleri daha yüksek bulundu $(p=0,029)$. Demir hindi şerbeti grubu 1.hafta ve 
4. hafta verilerinde istatistiksel olarak anlamlı farklılık tespit edildi. 4. hafta değerleri daha yüksek bulundu $(p=0,017)$. Türk kahvesi grubu 1.hafta ve 4 . hafta verilerinde istatistiksel olarak anlamlı farklılık tespit edilmedi $(p>0,05)$. Sadece içeceklerin renk değişimi üzerinde etkisi değerlendirildiğinde en yüksek renk değişimi demirhindi şerbeti solüsyonunda bekletilen örneklerde gözlendi.

\section{TARTIŞMA}

Diş hekimliğinde kullanılan geçici restorasyon materyallerinde renk değişimini etkileyen faktörler arasında sıvı emilimi, polimerizasyon miktarı, yüzey pürüzlülüğü ve materyal kalınlığı yer almaktadır. ${ }^{16}$ Bu çalışmada da kullanılan materyaller üretici firmanın talimatlarına uygun olarak polimerize edilmesi sağlandı. Aynı şekilde benzer çalışmalarda olduğu gibi tüm örnekler $2 \mathrm{~mm}$ kalınlığında hazırland.. ${ }^{16,17,18}$ Ağız ortamına maruz kalan dental materyallerin tümünde yüzeyin pürüzlülüğü renk değişimini etkileyeceği için yüzeyin mümkün olduğu kadar pürüzsüz ve parlak olması istenir. Bu çalışmada da tüm örnek yüzeyleri standart parlatma işlemleri ile pürüzsüz hale getirildi ve ağız ortamına uygun olması amacıyla solüsyonlara konulmadan önce 24 saat boyunca $37^{\circ} \mathrm{C}$ distile suda bekletildi. ${ }^{17}$ Dental materyallerde belirli işlem ve belirli süre sonucu ortaya çıkan renk değişiminin değerlendirilmesi birçok açıdan önemlidir. Çalışmamızda bu renk değişiminin öznel farklılıklar gözetilmeksizin nicel ölçümlerle değerlendirilebilmesi amacıyla spektrofotometrik cihaz kullanıldı. Bu cihaz sayesinde $L * a * b *$ parametreleri kullanılarak renk değişikliği farkı $\Delta \mathrm{E}$ olarak hesaplandı. Ölçülen iki renk için hesaplanan $\Delta \mathrm{E}$ değeri 0 olduğunda renk farklılğı "mükemmel", 0,5 ile 1,5 arasında olduğunda "çok iyi", 1 ile 2 arasında "iyi", 2 ile 3,5 arasında klinik olarak "kabul edilebilir" ve 3,5'ten fazla olduğunda klinik olarak "kabul edilemez" olarak tanımlanmaktadır. ${ }^{18}$ Bu çalışmada da $\Delta \mathrm{E}$ 3.5' ten az olduğunda "kabul edilebilir" ve $\Delta \mathrm{E} 3.5^{\prime}$ ten fazla olduğunda "kabul edilemez" olarak nitelendirildi.19 Bu çalışma ile elde edilen $\Delta \mathrm{E}$ değerleri incelendiğinde polimetilmetakrilat (PMMA) yapısındaki Temdent ve İntegra materyalleri sadece Türk kahvesinde 3.5 'in üstünde değer vermiştir. PMMA içerikli geçici materyallerindeki renk değişimi yüksek reçine içeriği ve elle manipülasyonu sonucu oluşan daha yüksek gözeneklilikten kaynaklanıyor olabilir. ${ }^{20,21}$ Türker ve arkadaşlarına göre ${ }^{14,}$ gıda ve içeceklerden elde edilen pigmentler, daha gözenekli olan akrilik reçinelerde daha yüksek renk değişikliğine neden olmaktadır. Braden ve arkadaşlarına göre ${ }^{22}$ PMMA içerikli materyallerdeki renk değişikliği, daha yüksek su emilim gücüne (adsorpsiyon ve absorpsiyon süreçlerinden herhangi biri veya her ikisi) bağlı olabilir.

Genellikle bis-akrilik kompozit rezin içerikli geçici materyalleri (Protemp, Systemp) renk değişikliği bakımından daha kararlı olması beklenir. Bunun nedeni tabanca ile otomatik olarak karıştıııması ile hava tutma ve gözenekli- lik miktarının azaltılması olarak açıklanabilir.10 Bu çalışmada Systemp distile su, şalgam suyu ve demirhindi şerbetinde 3.5 'in altında $\Delta \mathrm{E}$ değeri verirken Türk kahvesinde 3.5 'in üzerinde değer vermiştir. Normalde Türk kahvesi solüsyonunda bekletilen örneklerin yüzeyinde biriken plağın belirli kalınlığa ulaştıktan sonra yüzeyden kopması renk değişimini azaltır. ${ }^{23}$ Ancak Systemp'te görülen bu renk değişimi örnek üzerindeki plağın çözünmemesi ile açıklanabilir. Çalışmamızda bis-akrilik kompozit rezin esaslı Protemp materyali ise en fazla renk değişimi gösteren geçici materyaldir. İçeriğindeki modifiye reçine sayesinde su emilim miktarı azalması ile renk değişimindeki artış açıklanabilir. ${ }^{24}$

Araştırma çalışmalarında sıklıkla kullanılan solüsyonlar çay, şarap, kola, hazır toz kahve gibi içeceklerdir. Bu anlamda çalışmamızın farklılığı demirhindi şerbeti, şalgam suyu ve Türk kahvesi gibi geleneksel içeceklerin kullanıması olmuştur. Buna göre materyal farkı gözetilmeksizin çalışmada kullanılan içeceklerin meydana getirdiği renk değişimi değerlendirildiğinde en yüksek $\Delta \mathrm{E}$ değerlerini sırasıyla Türk kahvesi, demirhindi şerbeti, şalgam suyu tarafından meydana geldiği gözlenmiştir. Çalışmamızda kullanılan materyallerinin demirhindi şerbeti karşısında renk değişimine hassas olduğu gözlendi $(p<0,05)$. Bağlar ve arkadaşlarına göre çeşitli baharatlar içeren demirhindi şerbetinde renk değişimi sebebinin tanen, tartarik asit ve fenoller gibi sekonder metabolitlerin olduğunu düşünülmektedir. ${ }^{25}$ Şalgam suyunun oluşturduğu renk değişimine içeriğinde bulunan mor havuç ve şalgam turpu gibi doğal renklendiricilerin sebep olduğu düşülmektedir $(p<0,05)$. Çalışmamızda Türk kahvesi ilk 1 hafta sonunda en yüksek renklenmeyi gösterse de 4 hafta sonunda örneklerin renginde önemli bir değişiklik gözlenmemiştir. Buna göre distile su ve Türk kahvesi geçici materyallerinde istatistiksel olarak anlamlı fark göstermeyen düşük düzeyde renk değişimine sebep olmuştur ( $p>0,05)$.

Ayrıca, bu çalışmada, bir spektrofotometre üzerinde kaydedilen renk değişikliği miktarı ile klinik ortam arasındaki ilişkiyi belirlemek için UBS kriterleri kullanılmıştır. UBS kriterleri Tablo 3 'te belirtildi. UBS değerlerine göre klinik olarak en fazla renk değişiminin izlendiği solüsyon Türk kahvesi olmuştur.

Renk değişimi bu çalışmada test edilen içeceklerin yanı sıra kişiden kişiye farklııı gösterir ve ağız içerisinde tükürük ve içerdiği enzimler, tüketilen yiyecek ve içecekler, ISI değişimleri, sigara, kötü oral hijyen gibi faktörlere bağlıdır. Bu ve benzeri çalışmalarda tüm bu faktörleri içerecek şekilde ideal deney koşullarının taklit edilmemesi çalışmanın limitasyonlarındandır. ${ }^{19}$ Çalışma için hazırlanan örneklerin klinik koşullardan farklı olarak tükürük içermeyen yapay bir solüsyon içerisinde bekletilmesi, çalışmalarda hazırlanan örneklere polisaj işlemi uygulansa da dişlerdeki anatomik oluklar, fossalar klinik şartlarda ideal polisajı en- 
gellemesi de çalışmanın sınırlamaları arasındadır. ${ }^{17}$ Fakat bununla birlikte çalışmamızda kullanılan örnek sayısının fazla olması, materyal grup çeşitliliği olması ve toplumun günlük hayatta tükettiği içeceklerin kullanılması bizim için avantajdır. Dolayısıyla geçici materyallerinin daha uzun klinik kullanım süresini karşılayabilmeleri için hekimler tarafından alınan anamnez ve klinik şartlara uygun yapılması geçici restorasyonların başarısını ve ömürlerini arttırmak için gereklidir.

\section{SONUÇ}

Geçici restorasyonların renk değişimi, kullanılan materyale ve içeceğin tipine göre değişim göstermektedir. Çalışmamızda materyaller arası değerlendirmede en fazla renk değişimi bis-akril kompozit rezin içerikli Systemp 'te gözlendi. Aynı rezin içerikli Protemp materyali ise en fazla renk değişimi gösteren materyal oldu. İçecekler arası değerlendirmede en fazla renk değişimi demirhindi şerbetinde gözlendi ve bunu şalgam suyunun izlediği görüldü.

\section{KAYNAKLAR}

1. Gratton DG, Aquilino SA. Interim restorations. Dent Clin North Am 2004; 48 (2): 487-497.

2. Rosensteil, Land, Fujimoto. Cointemporary fixed prosthodontics. 4th ed. St Louis, Missouri: Elsevier Publishers; 2010.p.466

3. Christensen GJ. Provisional restorations for fixed prosthodontics. J Am Dent Assoc 1996; 127 (2): 249-252.

4. Rayyan MM, Aboushelib M, Sayed NM, Ibrahim A, Jimbo $R$. Comparison of interim restorations fabricated by CAD/CAM with those fabricated manually. J Prosthet Dent 2015; 114 (3): 414-419.

5. Burns DR, Beck DA, Nelson SK. A review of selected dental literature on contemporary provisional fixed prosthodontic treatment: Report of the Committee on Research in Fixed Prosthodontics of the Academy of Fixed Prosthodontics. J Prosthet Dent 2003; 90 (5): 474-497.

6. Scotti R, Mascellani SC, Forniti F. The in vitro color stability of acrylic resins for provisional restorations. Int $\mathrm{J}$ Prosthodont 1997; 10: 164-168.

7. Ferracane JL. Correlation between hardness and degree of conversion during the setting reaction of unfilled dental restorative resins. Dent Mater 1985; 1: 11-14.

8. Ferracane JL, Moser JB, Greener EH. Ultraviolet lightinduced yellowing of dental restorative resins. J Prosthet Dent 1985; 54: 483-487.

9. Gupta G, Gupta T. Evaluation of the effect of various beverages and food material on the color stability of provisional materials. An in vitro study. J Conserv Dent 2011; 14: 287-292.

10. Sham, AS, Chu, FC, Chai, J, Chow TW. Color stability of provisional prosthodontic materials. J Prosthet Dent 2004; 91 (5): 447-452.

11. Haselton DR, Diaz-Arnold AM, Dawson DV. Color stability of provisional crown and fixed partial denture resins.
J Prosthet Dent 2005; 93(1): 70-75.

12. Wagner WC, Kawano F, Dootz ER, Koran A: Dynamic viscoelastic properties of processed soft denture liners: Part II-Effect of aging. J Prosthet Dent 1995; 74: 299-304. 13. Khokhar ZA, Razzoog ME, Yaman P. Color stability of restorative resins. Quintessence Int 1991; 22: 733-737.

14. Turker SB, Kocak A, Aktepe E. Effect of five staining solutions on the colour stability of two acrylics and three composite resins based provisional restorations. Eur $\mathrm{J}$ Prosthodont Restor Dent 2006; 14: 121-125.

15. Haselton DR, Diaz-Arnold AM, Dawson DV. Color stability of provisional crown and fixed partial denture resins. J Prosthet Dent 2005; 93: 70-75.

16. Bayindir F, Kurklu D, Yanikoglu ND. The effect of staining solutions on the color stability of provisional prosthodontic materials. J Dent 2012; 40: 41-46.

17. Rutkunas $\mathrm{V}$, Sabaliauskas $\mathrm{V}$, Mizutani $\mathrm{H}$. Effects of different food colorants and polishing techniques on color stability of provisional prosthetic materials. Dent Mater J 2010; 29:167-176.

18. Turgut S, Bagis B, Ayaz EA, Ulusoy KU, Altintas $\mathrm{SH}$, et al. Discoloration of provisional restorations after oral rinses. Int J Med Sci 2013; 10: 1503-1509.

19. Bankoğlu GM, Karakoca NS, Turhan BB, Doğan A. Farklı içeceklerde bekletilen geçici restorasyon materyallerinin renk stabilitelerinin karşılaştırılması. Acta Odontol Turc 2016; 33 (2): 80-85

20. Inokoshi S, Burrow MF, Kataumi M, Yamada T, Takatsu T. Opacity and color changes of tooth colored restorative materials. Oper Dent 1996; 21:73-80.

21. Arima T, Murata $H$, Hamanda T. The effects of crosslinking agents on the water sorption and solubility characteristics of denture base resins. J Oral Rehabil 1996; 23:476-480.

22. Braden M, Causton EE, Clarke RL. Diffusion of water in composite filling materials. J Dent Res 1976; 55: 730-732. 23. Keskin $S$. The treatment of prosthetic dental materials with hypchlorite. MSc thesis, Middle East Technical University, Ankara, Turkey 2002.p.36

24. Givens EJ Jr, Neiva G, Yaman P, Dennison JB. Marginal adaptation and color stability of four provisional materials. J Prosthodont 2008; 17: 97-101.

25. Baglar S, Keskin E, Orun T, Es A. Discoloration Effects of Traditional Turkish Beverages on different Composite Restoratives. J Contemp Dent Pract 2017; 18 (2): 83-93. 